\title{
Biological risk in aviation
}

\begin{abstract}
This article intends to alert the general public, specially aviation and health professionals, to the dangerous influence aviation experts on the propagation of infectious diseases around the world. It's shown here how the massive and constant people transportation to all parts of the planet can act as an 'epidemic trigger', spreading contagious diseases very quickly throughout the globe. Furthermore, it's pointed out that there is a current need to develop a more effective prevention system in order to manage this risk more effectively.
\end{abstract}

Keywords: aviation, health, diseases, epidemic trigger
Volume 2 Issue 2 - 2018

\author{
Diego RigamonteVasconcelos,' Roberto \\ Marcio Dos Santos ${ }^{2}$ \\ 'Academic of the course of graduation in Aeronautical Sciences, \\ Pontifical Catholic University of Goias, Brazil \\ ${ }^{2}$ Master in Aviation Safety and Airworthiness Continued by ITA, \\ Master in Psychology from UFRGS, Controller of Air Traffic by \\ the Brazilian Air Force, Professor at the Aeronautical Sciences \\ course, Pontifical Catholic University of Goias, Brazil
}

Correspondence: Diego Rigamonte Vasconcelos, Academic of the course of graduation in Aeronautical Sciences, Pontifical Catholic University of Goias, Brazil, Email diegorvas@gmail.com

Received: October 31, 2017 | Published: March 12, 2018

\section{Introduction}

Aviation represents a great leap of humanity in the most diverse aspects, but with it also came risks that must be carefully managed. Among them is the biological risk, object of analysis of this work, that NR $32^{1}$ defines as "the probability of exposure to biological agents", which are, in turn, "microorganisms, genetically modified or no; cell cultures; parasites; toxins and prions." "In the context of aviation, the biological risk is in particular the susceptibility of the human body to diseases and other complications caused by microorganisms which find favorable conditions for their proliferation and manifestation within aircraft cabins. Firstly, it is explained how commercial aviation contributes to the spread of diseases around the world. Next, an approach is taken on measures to be taken by the Aircraft Commander (CMTE) in case of suspected biological threat on board, based on the current regulations. The next point is the close relationship between aviation and the spread of the Ebola virus, a situation that has occurred very recently, which has been a major concern of governments all over the world. The next topic concerns the forms of contagion during the flight, based on research conducted by various institutions, and finally a critique of how the issue of biological risk in aviation is addressed today.

This article was elaborated, mainly, based on: didactic texts on medicine and biology; periodicals of international circulation; regulations in the field of civil aviation; quantitative research and health safety protocols. The main problem that aviation poses, related to biological risk, is to be a potential trigger for the spread of epidemics across the globe, due to the rapid, massive and incessant transport of passengers and cargo around the world. It makes for much more interaction between distant people. Thus, a disease that may arise in a very distant place can spread very rapidly throughout the world, so that current medical-pharmaceutical technology does not have enough time to develop countermeasures before significant damage has already been caused. ${ }^{3}$ In addition to the interaction between people on a global scale, there are other factors linked to aviation that also contribute to the spread of infections. A passenger with an illness may have his or her condition aggravated during flight due to psychological reasons such as anxiety or nervousness and other conditions provided by the cabin environment, such as poor oxygenation, low relative humidity and sudden pressure and force G, which causes stress and fatigue to the organism. ${ }^{4}$ All of these factors also increase the human body's vulnerability to infectious diseases, as viruses in particular tend to spread more easily in low-moisture environments due to compromised mucosal membranes, important tools of the immune system. And the fatigue caused by exposing the body to high altitudes also impairs the performance of its defenses. For these reasons, it is not recommended, for example, that infants less than three months of age travel on air travel, as they do not yet have a sufficiently strong immune system. ${ }^{4}$

\section{Performance of the aircraft commander in case of suspicion of biological threat}

In the face of these circumstances, a rather delicate situation arises because, according to Art. 168 of the Brazilian Aeronautical Code, ${ }^{5}$ "The commander exercises authority over the persons and things that are on board the aircraft, and may disembark any of them, as long as it compromises good order, discipline or jeopardizes the safety of the aircraft or persons and property on board. "So if he suspects that a passenger has an illness that could endanger his or her health or that of other passengers during the flight, it may prevent him from flying. But one must be careful how this measure is adopted. If the passenger feels disrespected or humiliated in the face of such a situation, he or she may be brought to justice, according to the National Association for the Defense of the Rights of Air Passengers (ANDEP). Thus, it is up to the CMTE to make the final decision, but he should be aware of this, being cautious about the treatment given to the passenger and not going beyond the limits of what is considered appropriate and respectful. The case of Brazilian choreographer Deborah Colker was almost unknown in 2013. She was almost prevented from flying with her grandson because he had a disease called epidermolysis bullosa-a non-contagious disease, characterized by the appearance of blisters on the skin, mucosa. For her, the treatment she received was extremely shameful. In that case, a lawsuit would then be filed.

Against this background, it is recommended that passengers with contagious, cardiac, respiratory or postoperative diseases carry a medical certificate that guarantees that they are not endangering 
their own health or the health of the other passengers of the flight. The doctor Vânia Melhado, president of the Brazilian Society of Aerospace Medicine (SBMA), when asked about the subject, said: "The same disease can leave a person incapable of traveling at one time and fit in another." Chicken pox and tuberculosis are good examples of this, since they make travel unfeasible only when they are in a transmissible stage, and do not represent danger when they cease to be contagious. Hence the importance of the certificate to prove this situation. ${ }^{6}$ It is common to find on the websites of the companies themselves the Medical Information Form (MEDIF), which is a form on disease behavior during a flight, internationally standardized by the International Air Transport Association (IATA), which represents most airlines of the world. It must be completed by the passenger's doctor and delivered to the airline before the trip, and the medical department of the same will evaluate the case, determining whether or not the passenger can board the flight. If the passenger chooses to carry a common certificate, it should be stated categorically that the trip will not aggravate the illness, and that it does not present a risk of contagion to other passengers. ${ }^{7}$

The International Civil Aviation Organization (ICAO), which regulates civil aviation worldwide through its 19 Annexes, establishes in Annex 2: Air Rules, regulated in Brazil by ICA 100-12-Instruction of the Aeronautics Command, ${ }^{8}$ that the CMTE reports to the air traffic service provider organ-ATS-any suspicion of a passenger with a communicable disease or any other public health risk, with the purpose of facilitating and expediting, at the destination aerodrome, the provision of personnel medical equipment and specific equipment for the situation. This message shall include: aircraft identification, departure aerodrome, destination aerodrome, estimated time of arrival, number of persons and suspected cases on board and the nature of the risk to public health, if known. The ATS body concerned shall then pass on the information to the departure ATS body in order to prevent the spread of the disease from other aircraft departing from the same aerodrome; to the destination ATS body, which shall inform the airport administration, stating the need for contact with the competent public health body and the aircraft operator, which may be, for example, an airline. In Annex 9- Facilitation, ${ }^{9}$ passengers with fever- $38^{\circ} \mathrm{C}$ or $100^{\circ} \mathrm{F}$ or higher-associated with other symptoms such as: malaise, persistent cough, compromised breathing, diarrhea, vomiting persistent skin rashes, scars or bleeding without prior injury should draw the crew's attention to potential biological risk. If the hazard is found, it shall be considered a communicable disease case on board, and the CMTE shall promptly inform the controller, as described in the previous paragraph. It is also envisaged that aircraft requiring at least one cabin crew member- commissioner-must contain at least one kit of medical equipment. This kit should be used to sanitize some potentially infectious body and to protect the crew from possible contagion due to contact with fluids from it, such as blood and urine.

There are also references in Annex $9^{9}$ to the so-called Public Health Passenger Locator Card. It basically consists of a form developed by the World Health Organization (WHO), which must be completed by passengers during the flight or at the time of landing and delivered to the competent authority when they are suspicious of passengers with communicable disease on the flight. It will contain information that will enable public authorities to quickly track down anyone who has been exposed to increased risk of contagion during the trip, taking into account, in particular, the location of their seat, which will be identified in a 'risk map' developed by specialists. This is a public health control measure that, according to ICAO, IATA and WHO, should be used promptly in the event of an outbreak in any country with which air operations are carried out.
Item 8.16 of Annex $9^{9}$ requires the Contracting State to establish a national aviation plan as a precautionary measure in the event of an outbreak of a contagious disease which endangers public health. The first note of the item informs you that guidelines for this are found on the ICAO website on Aviation Medicine and the second, that air traffic management bodies, together with aerodromes, should establish, respectively, contingency plans and contingency plans in aerodromes for the risk in question, according to Annexes 11-Air Traffic Services and 14-Aerodromes. The CMTE should also be alert to procedures and protocols established by the airline itself. In Brazil, companies adopt certain safety policies, based on resolutions of the Federal Council of Medicine and Sanitary Surveillance Bodies. ${ }^{6}$ The CMTE should also consult the Aeronautical Information Publications (AIPs) of the countries of origin and destination to inform themselves of their respective health related legal requirements. It is stated in AIP Brasil, ${ }^{10}$ for example, that public health measures are not applied to aircraft operating in this country, unless they come from an infected area. In this case, the aircraft shall be disinfected, upon arrival, by the local Health Authority, with its doors and windows closed and ventilation systems shut down, throughout the procedure.

\section{Ebola and aviation}

During the Ebola crisis in 2014, at a meeting of its Emergency Committee in Geneva, which had representatives from its 194 member countries, the WHO defined a number of criteria to hinder the spread of the virus. ${ }^{11}$ In countries where cases of the disease have been recorded, especially those most affected, such as Guinea, Liberia and Sierra Leone, passengers presenting symptoms of the disease should be examined before boarding, and no person would be allowed to travel with any malaise that might be the Ebola, unless in case of medical transfer. According to Keiji Fukuda, deputy to Margaret Chan, director general of the organization: "The WHO does not recommend banning travel and trade, unless it is specifically about people infected or who have been in contact with a patient". ${ }^{12}$ In practice, however, it was quite different. Several airlines have canceled their flights to countries in crisis, showing they have enough autonomy to take their own measures when it comes to the safety of its passengers and staff, starting with Emirates, which suspended its flights on August 2, 2014 to Guinea. Subsequently, on 5 August 2014, British Airways suspended operations for Sierra Leone and Liberia for one month, stating that it had taken such action due to the deteriorating public health condition in those two countries, and that security of their crews, passengers and solo teams would always be the company's priority.

Thus, according to the company spokesperson, customers who had marked travel could request reimbursement, or redial it to a later date. ${ }^{13}$ Subsequently, Korean Air suspended its flights to Kenya on 14 August 2014, even though no case of Ebola had been reported in that country until then. The operations of the ASKY company in Nigeria were also suspended following the arrival of the American Patrick Sawyer, who was infected and died shortly thereafter. ${ }^{14}$ Sawyer contracted the disease in Liberia, when he took care of his sister, who carried Ebola. He had already had the symptoms of the disease before even taking his two flights, which put him in contact with 59 people: the first from Liberia to Togo by ASKY Airlines and the second from Togo to Nigerian capital Lagos. ${ }^{15}$ According to the Civil Aviation Authority of Nigeria (NCAA), the airline ASKY did not demonstrate any capacity to prevent the arrival of contaminated passengers to Nigeria. The Nigerian government has therefore ordered the suspension of its operations in its territory. ${ }^{16}$ According to Correa, ${ }^{17}$ researchers analyzed air traffic data in 220 countries in order 
to predict possible patterns of spread of the disease around the world and, due to the great intensity of aircraft circulation in the airports of Rio de Janeiro and São Paulo, Brazil was dangerously considered the gateway to the virus in Latin America.

\section{Control measures at airports aiming at containing the spread of Ebola}

In the African countries most affected by the epidemic, the passengers were, from an early stage, tested to detect the disease. At the time of shipment, they answered questions related to the Ebola and had their temperatures measured by an infrared thermometer. In case of any suspicion of Ebola, they were prevented from embarking. But it was only after the disease reached countries in other continents that governments in other parts of the world warned themselves of their danger. As a result, these procedures were carried out at several international airports, in several other countries. Two cases that contributed to the international alarm and became known worldwide were the Liberian Thomas Duncan in the US and Theresa Romero in Spain. ${ }^{18}$ Romero, a nurse who was contaminated in Spain herself when treating an infected patient from Sierra Leone, is now one of the survivors of the disease. But Duncan's case was different. Having acquired Ebola still in Liberia, he embarked on a flight to the USA without difficulty, not even knowing that he was infected. He checked the temperature three times before boarding, according to the procedures adopted in that Country: at the gate, before entering the airport parking lot; at the terminal and at the time of shipment, and answered 'no' to the questionnaire questions regarding the symptoms of the disease and recent physical contact with patients. However, the long period of incubation of the virus-time from infection to the onset of symptoms-ranging from 2 to 21 days, made all these tests ineffective for the Liberian, who did not present at the time they were symptoms of the disease. He only came to develop them a week after his arrival in the USA, where he died a few days later, and infected two nurses who cared for him. ${ }^{19}$

Soon after these events, these same control procedures were also carried out at US airports, starting with JFK airport in New York, and later extending to other international airports: Chicago O'Hare, Washington Dulles, Atlanta Hartsfield- Jackson, and Newark Liberty in New Jersey. US immigration officials estimated that about 150 people traveled daily from one of the three countries suffering from an outbreak of Ebola-Guinea, Liberia and Sierra Leone-to the United States, and that $95 \%$ of them landed at one of these five airports. Although there are no direct flights between these countries and the US, officials from the US Customs and Border Protection (CBP) are able to determine the exact provenance of each passenger, even though he has made several connections. ${ }^{20}$ In the United Kingdom, the measures were adopted at the two most important airports in the country: Heathrow and Gatwick, both in London. France, for its part, began to carry out the screening at Charles de Gaulle airport in Paris. ${ }^{20}$ A number of criticisms were made of these measures. Regarding temperature gauging, the possibility arose of the passenger to ingest drugs that would disguise the symptoms of the disease, including fever. As for the questionnaire, passengers could simply lie to avoid raising suspicions. But the most alarming concerns were undoubtedly concerning the long overdue incubation period of the virus, a decisive factor that could simply render all such security procedures useless, as in the case of Duncan. ${ }^{20}$ So far, the only safe form of inspection that is known and that circumvents all these difficulties is the conduct of blood tests, because they leave no doubt as to the presence of the virus. But for this, it is necessary that there be laboratories in the places where the analyzes are desired, making this procedure very difficult in airports. In addition, the large number of passengers to be tested makes this option even more difficult. ${ }^{21,22}$

\section{Procedures established in Brazil for suspected cases of Ebola in aircraft}

In Brazil, the Ministry of Health established during the Ebola crisis a series of procedures to be adopted in case of suspected infected passenger, through the Protocol for the Surveillance and Management of Suspected Cases of Ebola Virus. ${ }^{23}$ These are: information prior to the destination airport which, in turn, would immediately activate the nearest National Agency of Sanitary Surveillance Agency (ANVISA). This would initiate the necessary procedures for the evaluation of the case, triggering the Mobile Emergency Service (SAMU) or other service indicated by the State Department of Health in question. If it were really considered a suspect and if the patient was in a position to be removed, aeromedical transport should be initiated. The patient would be transported directly from the aircraft in which he arrived at the aircraft that would take him to the national reference hospitalNational Institute of Infectology Evandro Chagas/Fiocruz, RJ. If transportation to the hospital was not possible, the patient should be taken to the state referral hospital. Then, a team from Posto da Anvisa would interview passengers and crew for the identification of contact persons-people sitting immediately next to the suspect, escorts or anyone else who has had some type of bodily contact-who, in turn, would be accompanied by State Department of Health. Lastly, the cleaning and disinfection of the aircraft would be carried out, following strictly the procedures set forth in ANVISA's Contingency Plan and Emergency Response in Public Health for Entry Points, which contains all the guidelines for execution.

\section{Transmissibility of diseases in aircraft}

In addition to the aforementioned factors that promote the proliferation of diseases in an aircraft, it was also found that bacteria causing vomiting and various infections can survive for a considerable time inside. Armrests, seat pockets and other surfaces are places where they usually live for several days. Researchers at Auburn University have monitored bacteria Staphylococcus aureus-responsible for various skin diseases-and Escherichia coli-which causes intestinal diseases-and have applied them to various surfaces found inside an aircraft, such as supports, leathers, pockets and plastic seating trays, metal bathroom knobs and plastic window blinds. These surfaces were supplied by an airline and were exposed in laboratory to the typical conditions of an in-flight aircraft. The result was the survival for up to seven days of these bacteria. Thus, it is concluded that there is a considerable risk of transmission through contact with the skin. ${ }^{24}$

Mc Cartney ${ }^{25}$ points to studies indicating that the chances of contracting a flu on a plane ride are around $20 \%$. Most of the time, air is blamed on the cabin, which is recycled. However, it has been found that high efficiency air filters-HEPA filters, or High Efficiency Particulate Air-present in most of today's jets, can contain up to $99.97 \%$ of the airborne particles of bacteria and viruses. In addition, cabin air is renewed at least 20 times per hour of flight. The biggest problem is when the aircraft needs to stay on the ground for a long time without air circulation, as a 1979 study has found, which analyzed the transmissibility of diseases in an aircraft that remained in that situation for three hours. As a result, 39 , or $72 \%$ of the 54 passengers became ill within two days, due to the fact that a single passenger had the flu. 
Thus, the infection has the ability to spread at an incredible rate under these conditions. That is why the Federal Aviation Administration (FAA), the agency responsible for US aeronautical surveillance in 2003, advised that airlines should wait for passengers from their aircraft should be exceed thirty minutes. However, the adoption of this measure has not become mandatory.

According to McCartney, most of the transmissions happen not by cabin air but by contact with contaminated people and objects. Many of the dangers come from the hands, mouth and nose of the closest passengers. The risk area is two seats away, behind, ahead or sideways, according to a study in the journal 'Emerging Infectious Diseases,' published by the American Centers for Disease Control and Prevention (CDC). In 2009, an Australian survey looked at passenger contamination of the H1N1 flu virus-on long-haul flights. It was found that $2 \%$ of the passengers were sick during the flight and 5\%, one week after the landing. In addition, this survey indicated that a passenger sitting in the aforementioned risk area has a $7.7 \%$ chance of contracting the disease. As early as 2002, a US survey suggested a much larger display area. It was observed that a passenger seated by seven seats from another, who had the flu, contracted the disease, while the person sitting immediately next to him, did not. ${ }^{25}$

There are some precautions that can be taken, on the plane, to reduce the risks of infections. They are: washing your hands often with some alcohol-based solution, since passengers constantly touch their mouth, nose or eyes after touching another surface of the aircraft, such as the armrests of the seats; use some fabric to clean the trays before using them; avoid the pockets of the seats; open the air passage so that it passes in front of it, as directed filtered air will keep the 'dirty air' away; try a seat change if someone is coughing or splashing in the vicinity; avoid pillows and blankets distributed by the company; and sleep at least seven hours before the trip, to strengthen the body's immune system. ${ }^{26}$ A panel of the National Academy of Sciences (NAS) in the United States conducted a two-year study, collecting samples from several airport areas, in an attempt to discover its most dangerous locations for agglomerations of infectious microorganisms. It was concluded that the areas of check-in, baggage handling and inspection are the most problematic due to the greater crowding of people. $^{27}$

\section{Final considerations}

When analyzing the way in which the biological hazard is handled today in aviation, the following question arises: Are people who represent a biological threat really being identified? Apparently no. The criteria used to identify passengers that may represent danger in this respect are somewhat vague, superficial. The cases covered in this paper, such as that of the American Patrick Sawyer, or the Liberian Thomas Duncan, are examples of this fragility: both were infected with Ebola and traveled normally. Sawyer's was perhaps the most serious, as he had already had symptoms before embarking, but he found no difficulties in taking his two flights, which put him in contact with 59 people. There was no one to stop him. There is, therefore, a major safety flaw. It is necessary to establish a well-defined prevention system, with more categorical rules and procedures, and to assign duties and responsibilities to the professionals involved in the flight. These, then, would have the task of watching over security from a biological point of view, and were prepared to do so. It is clear that the regulations only mention the procedures to be followed in case of biological risk on board, but it remains to be clearly stated what must be done to avoid this type of situation from the outset. An adequate distribution of skills is lacking, aiming to improve the management of this risk.

Perhaps the flight attendants themselves could receive some specific training in this area? Everything in aviation should be done with the utmost caution, following strictly specific and meticulous procedures, always aiming at reducing the risks involved in all operations. However, if it is so in all other respects, the treatment of biological risk should not be different, since it is also about the safety of all. The issues discussed here demonstrate that the influence of aviation on people's lives goes far beyond what one imagines at first. It covers safety aspects that go beyond the risk of aviation accidents and which, although they are less important than these, should not be neglected. This could be very well observed when the world witnessed in 2014 the crisis of the Ebola virus, which emerged in very limited territory of West Africa, but took on much larger dimensions from the moment it began to spread to other continents, aviation, which fulfilled nothing more than its role of providing the link between peoples. The presence, however, of passengers infected with this deadly virus has put at risk public health in all countries of the planet. Fortunately, now in 2015, the disease seems to be under control and no longer as worrisome as it was last year, but eventually revealed a number of safety gaps in the way aviation is currently conducted. These shortcomings should serve as a starting point for the development of a more effective system to combat the spread of diseases by air transport, before the possible emergence of another global risk situation, perhaps even more serious than that of Ebola.

\section{Acknowledgement}

None.

\section{Conflict of interest}

None.

\section{References}

1. NR 32-Safety and Health at Work in Health Care Facilities. Brazilian NR: Brazil; 2015.

2. Cardoso M. Prions. Info Escola: Brazil; 2015.

3. Airport Cooperative Research Program. Infectious Disease Mitigation in Airports and on Aircraft. Washington: Transportation Research Board; 2013. 30 p.

4. Berkow R, Beers MH, Bogin RM, et al. Problems in transit. MSD manual: USA; 2015.

5. Brazilian code of Aeronautics. Presidency of the republic civil house: Sub office for legal affairs. Planalto: Brazil; 1986.

6. By law, Pilot can bar sick passenger; see how to avoid problems. G1: Sao Paulo; 2013.

7. International Air Transport Association. Medical Manual. $6^{\text {th }}$ edn. Montreal, Quebec: Canada; 2013. 88 p.

8. ICA 100-12: Air Rules and Air Traffic Services. DF-Aeronautical Staff: Brazil; 2013.

9. International Civil Aviation Organisation. Annex 9. $13^{\text {th }}$ edn. Montreal, Quebec: Canada; 2011.90 p.

10. Ministry of Aeronautics. Aeronautical Information Publication. 2nd edn. AISWEB: Brazil; 2014. 204 p.

11. Ebola is an international public health emergency, says WHO. Folha politica: Brazil; 2014. 
12. WHO declares Ebola as public emergency of international reach. Exame: USA; 2014.

13. Alexandre S. For Fear of Ebola, British Airways Cancels Flights to Sierra Leone and Liberia. R7 Cheers: Brazil; 2014.

14. Emirates suspends flights to guinea by epidemia de Ebola. ODIA: Brazil; 2014.

15. James NYE. Ebola victim who sparked fears of a worldwide outbreak was American: Father who died of incurable virus in Nigeria after taking international flight was going to visit his children in Minnesota. Mail online: UK; 2014.

16. Nigeria suspends flights of airline in which it traveled victim of the ebola. Opera mundi: Brazil; 2014.

17. Correa A. Risk of Ebola Reaching Brazil is 5\%, Study says. BBC world news: Brazil; 2014.

18. Deutsche W. First patient diagnosed with ebola dies in US. DW: Made for minds; Brazil; 2014.

19. Botelho G. US Ebola patient: The travels and health travails of Thomas Eric Duncan. Cable news network(CNN): USA; 2015.
20. Smitha M. Ebola: airport tests do not detect infected without symptoms. BBC News: Brazil; 2014

21. Mark S. Are ebola tests reliable? Dr Sircus: Brazil; 2014.

22. Paulo G. What does it feel like to ride at absurd speeds? Tecmundo: Brazil; 2011.

23. Ministry of Health. Protocol for Surveillance and Management of Suspected Cases of Ebola Virus Disease. 1st edn. DF: Brazil; 2014. 15p.

24. Study: Bacteria can survive up to one week on aircraft. Exame: USA; 2014.

25. Scott Mc Cartney. Where Germs Lurk on Planes. The wall street journal: Brazil; 2011.

26. Rick S. How to Avoid Getting Sick on a Plane. abc News: USA; 2013.

27. Christine LG. Research on the Transmission of Disease in Airports and on Aircraft: Summary of a Symposium. TRB News: UK; JanuaryFebruary 2011. p. 34-35. 